\title{
Mean-Variance Model for Optimal Multinational Project Adjustment and Selection
}

\author{
Xiaoli Su, Xiaoxia Huang(Corresponding Author) \\ Dongling School of Economics and Management \\ University of Science and Technology Beijing \\ Beijing, 100083, China \\ E-mail: hxiaoxia@manage.ustb.edu.cn
}

\begin{abstract}
This paper discusses the multinational project adjustment and selection problem in which project parameters are regarded as random variables. In the paper, adjustment of foreign existing projects and selection of the new foreign projects are considered simultaneously. Typical cash flows and value sources of foreign projects are introduced and a meanvariance optimal multinational adjustment and selection model is proposed. As an illustration, a numerical example is also presented.
\end{abstract}

Keywords-project selection; project adjustment; capital budgeting; multinational; uncertain parameters

\section{INTRODUCTION}

With the globalization of economy, more and more companies seek to make project investment abroad. Besides, to make good use of investment capital, the companies should look for and choose beneficial new projects abroad on one hand. On the other hand, the existing overseas projects may have to be improved. For example, upgrading may be needed when there's a need to increase yields or better product quality. Or it may be better just give up some existing projects because of the change of customers' demand. This type of problem is foreign project adjustment and selection problem.

In the past, much attention has been paid to new projects selection in a domestic country. Weingartner ${ }^{[13]}$ made a major contribution to the theoretical formulation and treatment of the domestic new projects selection problem. To achieve the target of maximizing the net present value of the selected projects under budget constraint, he proposed an integer programming model by treat the investment parameters such as cash flows and available investment capital budget as deterministic numbers. Afterwards, this basic model was developed in order to increase its relevance and applicability to the real world situations, for example, some research was done on the processing of differences between borrowing rates and lending rates $^{[10]}$, and the integration of project portfolio selection, staff assignment and learning in a model ${ }^{[5]}$, etc. Lee and $\mathrm{Kim}^{[8]}$, Dickinson et al. ${ }^{[2]}$ discussed interdependent projection problem. Besides, Gemici-Ozkan et al. ${ }^{[4]}$ gave a three-phase decision support structure for a R\&D project portfolio selection and ShakhsiNiaei et al. ${ }^{[11]}$ developed a two-phase framework for projects selection under uncertainty and real world constraints.
Till now, only a small part of research was done on multinational projects selection. Booth ${ }^{[1]}$ studied the multinational capital budgeting frameworks. Zhang et al. ${ }^{[14]}$ gave a selection method for projects located in different countries. Lessard ${ }^{[9]}$ developed a multinational Adjusted Present Value (APV) method which is an extension of NPV method used in analyzing domestic projects selection. Other discussions can be found in the literature such as Shapiro ${ }^{[12]}$, Holland $^{[6]}$, and Eun and Resnick ${ }^{[3]}$ etc.

However, so far little research has been done on project selection considering both existing project adjustment and new project selection, not to mention the multinational project adjustment and selection with uncertain parameters. In this paper, we will discuss the multinational existing project adjustment problem together with new project selection. Besides, the project parameters such as net cash flows, upgrading expenditures and foreign exchange rate are all treated as random variables.

The rest of the paper is organized as follows. In Section 2, we will firstly describe a multinational project adjustment and selection problem, and then develop an optimization model for handling this problem. Next, we will present a numerical example in Section 3. Finally, in Section 4, we will give some concluding remarks.

\section{Multinational Project Adjustment And SELECTION MODEL}

To understand a foreign project adjustment and selection problem, let us consider a corporation which has $k$ numbers of independent projects in operation overseas. Because of the change of market environment and economic policy, the corporation may need to adjust some of the existing projects. For an existing project, there are three choices, i.e., keeping as it is, upgrading it and giving it up. Besides, the corporation can select some new projects from $n-k$ numbers of new independent candidate foreign projects. The products produced by the foreign projects either existing or newly selected are sold locally, which means that the profits earned are denominated in foreign currencies. The corporation's objective is to obtain a maximum investment return in the present value sense by adjusting the existing projects and/or selecting new projects. The constraint is the budget limitation. Suppose that the corporation used all its capital to build the existing projects, but now they can use both the bank loan and their own capital to make the investment. The corporation must make a 
decision at the beginning of the new decision year. Suppose each new invested project and upgraded projects needs one year to construct, and starts to earn money in the same year. In addition, suppose each existing and new project have no salvage at the end of lifetime. For description convenience, notations used are described as follows:

$d_{t i}$ :the net operating cash flow of the $i-t h$ foreign project denominated in the foreign country currency at the end of the $t$-th year;

$T_{i}$ :the end year of project $i$;

$f_{i}$ :the duration that the existing projects have existed, $i=1,2, \ldots k$;

$i_{u d}:$ the domestic required rate;

$i_{d}$ : the normal domestic borrowing rate;

$S_{t}$ : the exchange rate of home currency to the foreign country currency in the $t$-th year;

$r_{h}$ : corporation tax rate in the home country;

$r_{f}:$ corporation tax rate in the foreign country;

$D_{t i}$ : depreciation value of project $i$ denominated in the foreign country currency in the $t$-th year;

$b$ : the increasing rate of yield after upgrading;

$V_{i}$ :the book value of project $i$ when it is given up;

$G O_{i}$ :the upgrading expenditure of project $i$ at the beginning of the new decision year, $i=1,2, \ldots k$;

$I_{t i}$ : interest of loan for project $i$ denominated in the foreign country currency in the $t-$ th year;

$a_{i}$ : the initial construction cost of project $i$ denominated in the foreign country currency;

$W_{0}$ :the corporation's available own capital denominated in the home currency;

$a$ : the largest amount of loan granted denominated in the home currency at the beginning of the new decision year;

$\mathrm{NI}_{i}$ : the income of project $i$ if the project $i$ is given up and sold, $i=1,2, \ldots k$;

$x_{i}, y_{i}$ : decision variables which are defined by

$x_{i}=\left\{\begin{array}{l}1, \text { if project } i \text { is kept or selected, } \\ 0, \text { if project } i \text { is given up or not selected, }\end{array} i=1,2, \ldots, n\right.$,

and

$y_{i}=\left\{\begin{array}{l}1, \text { if project } i \text { is upgraded, } \\ 0, \text { otherwise, }\end{array} \quad i=1,2, \ldots, k\right.$,

For new project $i, i=k+1, k+2, \ldots, n$, the cash flows and the value sources of foreign projects should include the following terms:

The first term is the after tax net operating cash flow of the projects. Note that the foreign cash flows should be converted into the home country currency, thus the domestic rate is used here. The present values of the net operating cash flows from the $k$ numbers of candidate projects can be calculated as follows:

$$
F_{1 i}=\sum_{t=1}^{T_{i}} \frac{S_{t} d_{t i} x_{i}\left(1-r_{h} \vee r_{f}\right)}{\left(1+i_{u d}\right)^{t}}
$$

where $\vee$ denotes the maximal operator.

The second term comes from depreciation tax shields. The present values of depreciation tax shields can be calculated as follows:

$$
F_{2 i}=\sum_{t=1}^{T_{i}} \frac{S_{t} D_{t i} x_{i}\left(r_{h} \vee r_{f}\right)}{\left(1+i_{d}\right)^{t}}
$$

When we use straight line depreciation, we can have

$$
D_{t i}=\frac{a_{i}}{T_{i}}
$$

Therefore, the present value of depreciation tax shields become

$$
F_{2 i}=\sum_{t=1}^{T_{i}} \frac{S_{t} a_{i} x_{i}\left(r_{h} \vee r_{f}\right)}{T_{i}\left(1+i_{d}\right)^{t}}
$$

The third term comes from interest tax shields. The present values of interest tax shields can be calculated as follows:

$$
F_{3 i}=\sum_{t=1}^{T_{i}} \frac{S_{t} I_{t i} x_{i}\left(r_{h} \vee r_{f}\right)}{\left(1+i_{d}\right)^{t}}
$$

We use the levered borrowing rate here since the tax savings from both depreciation shields and interest shields are relatively less risky than net operating cash flows.

Let

$F_{4 i}=S_{0} a_{i} x_{i}$

Where $S_{0}$ is the spot foreign exchange rate of the home country currency to the foreign country at the beginning of the new decision year.

It is easy to see that the net present value (NPV) of the new project $i, i=k+1, k+2, \ldots, n$, can be calculated as follows:

$$
N P V_{i}=F_{1 i}+F_{2 i}+F_{3 i}-F_{4 i}
$$

Then the investment profits in NPV form from the selected new projects is

$$
\begin{aligned}
& O B_{1}=\sum_{i=k+1}^{\mathrm{n}} N P V_{i}=\sum_{i=k+1}^{\mathrm{n}}\left(F_{1 i}+F_{2 i}+F_{3 i}-F_{4 i}\right) \\
& =\sum_{i=k+1}^{\mathrm{n}} \sum_{t=1}^{T_{i}} \frac{S_{t} d_{t i} x_{i}\left(1-r_{h} \vee r_{f}\right)}{\left(1+i_{u d}\right)^{t}}+\sum_{i=k+1}^{\mathrm{n}} \sum_{t=1}^{T_{i}} \frac{S_{t} a_{i} x_{i}\left(r_{h} \vee r_{f}\right)}{T_{i}\left(1+i_{d}\right)^{t}} \\
& \quad+\sum_{i=k+1}^{\mathrm{n}} \sum_{t=1}^{T_{i}} \frac{S_{t} I_{t i} x_{i}\left(r_{h} \vee r_{f}\right)}{\left(1+i_{d}\right)^{t}}-\sum_{i=k+1}^{n} S_{0} a_{i} x_{i}
\end{aligned}
$$

For the existing project $i, i=1,2, \ldots, k$, there are three choices, i.e., keeping as it is, upgrading it and giving it up. Firstly, consider upgrading. Suppose the yields will increase at a rate of $b$ after upgrading. Then the cash flows and the value sources of foreign projects after upgrading should include the following terms:

$$
\begin{aligned}
F_{1 i} & =\left(1+b y_{i}\right) \sum_{t=1}^{T_{i}} \frac{S_{t} d_{t i}\left(1-r_{h} \vee r_{f}\right)}{\left(1+i_{u d}\right)^{t}} \\
F_{2 i} & =\sum_{t=1}^{T_{i}} \frac{S_{t} D_{t i}\left(r_{h} \vee r_{f}\right)}{\left(1+i_{d}\right)^{t}} \\
D_{t i} & =\frac{a_{i}-\frac{a_{i}}{T_{i}+f_{i}} f_{i}+y_{i} G O_{i}}{T_{i}} \\
F_{3 i} & =\sum_{t=1}^{T_{i}} \frac{S_{t} I_{t i} y_{i}\left(r_{h} \vee r_{f}\right)}{\left(1+i_{d}\right)^{t}}
\end{aligned}
$$




$$
F_{4 i}=S_{0} G O_{i} y_{i}
$$

Meanwhile, the initial outlay previously spent has become a sunk cost and won't have any effect on the choice now. However, the future net cash flows of the existing project $i$ if it is not adjusted from now to the end year should be regarded as the opportunity cost. Let $O N P V_{i}$ denote the opportunity cost of the existing project $i, i=1,2, \ldots, k$, It can be calculated as follows:

$$
O N P V_{i}=\sum_{t=1}^{T_{i}} \frac{S_{t} d_{t i}\left(1-r_{h} \vee r_{f}\right)}{\left(1+i_{u d}\right)^{t}}+\sum_{t=1}^{T_{i}} \frac{S_{t} a_{i}\left(r_{h} \vee r_{f}\right)}{\left(T_{i}+f_{i}\right)\left(1+i_{d}\right)^{t}}
$$

It is easy to see that the net present value of the upgraded project $i, i=1,2, \ldots, k$, can be calculated as follows:

$A_{i}=F_{1 i}+F_{2 i}+F_{3 i}-F_{4 i}-O N P V_{i}$

Next, consider if the existing project $i$ is given up. In this case, the net present value of the given up project $i$, $i=1,2, \ldots, k$, can be calculated as follows:

$B_{i}=S_{0} N I_{i}-S_{0}\left(N I_{i}-V_{i}\right)\left(r_{h} \vee r_{\mathrm{f}}\right)-O N P V_{i}$

$V_{i}=a_{i}-\frac{a_{i}}{T_{i}+f_{i}} f_{i}$

Thus, the investment profits in NPV form from the existing projects is

$$
\begin{aligned}
& O B_{2}=\sum_{i=1}^{\mathrm{k}}\left[A_{i} x_{i}+B_{i}\left(1-x_{i}\right)\right]=\sum_{i=1}^{k}\left[\left(1+\mathrm{b} y_{i}\right) \sum_{t=1}^{T_{i}} \frac{S_{t} d_{t i}\left(1-r_{h} \vee r_{f}\right)}{\left(1+i_{u d}\right)^{t}}\right. \\
& +\sum_{t=1}^{T_{i}} \frac{S_{t}\left(a_{i}-\frac{a_{i}}{T_{i}+f_{i}} f_{i}+y_{i} G O_{i}\right)\left(r_{h} \vee r_{f}\right)}{T_{i}\left(1+i_{d}\right)^{t}}+\sum_{t=1}^{T_{i}} \frac{S_{t} I_{t i} \mathrm{y}_{i}\left(r_{h} \vee r_{f}\right)}{\left(1+i_{d}\right)^{t}} \\
& \left.-S_{0} G O_{i} y_{i}-\sum_{t=1}^{T_{i}} \frac{S_{t} d_{t i}\left(1-r_{h} \vee r_{f}\right)}{\left(1+i_{u d}\right)^{t}}-\sum_{t=1}^{T_{i}} \frac{S_{t} a_{i}\left(r_{h} \vee r_{f}\right)}{\left(T_{i}+f_{i}\right)\left(1+i_{d}\right)^{t}}\right] x_{i} \\
& +\sum_{i=1}^{k}\left[S_{0} N I_{\mathrm{i}}-S_{0}\left(N I_{\mathrm{i}}-a_{i}+\frac{a_{i}}{T_{i}+f_{i}} f_{i}\right)\left(r_{h} \vee r_{\mathrm{f}}\right)\right. \\
& \left.-\sum_{t=1}^{T_{i}} \frac{S_{t} d_{t i}\left(1-r_{h} \vee r_{f}\right)}{\left(1+i_{u d}\right)^{t}}-\sum_{t=1}^{T_{i}} \frac{S_{t} a_{i}\left(r_{h} \vee r_{f}\right)}{\left(T_{i}+f_{i}\right)\left(1+i_{d}\right)^{t}}\right]\left(1-x_{i}\right)
\end{aligned}
$$

The exact values of most parameters used in the paper are difficult to predict due to the complex and changeful market environment, thus, we treat these parameters as random variables in the paper. We cannot directly maximize the net present value of the project portfolios since the project parameters are random variables now. To solve the project selection problem with fuzzy variables, Huang ${ }^{[7]}$ proposed a fuzzy mean-variance project selection model. Here, we will follow the idea to propose a mean-variance multinational project selection and adjustment model. We use the expected value of the investment profits as the representative and maximize it. Then the corporation's aim can be expressed as follows:

$$
\max E\left[O B_{1}+O B_{2}\right]
$$

where $E$ is the expected value operator. Using variance as the risk measurement, the corporation can ask that the variance value of the investment return not to exceed a preset level. Then we can express the return risk control requirement as follows:

$$
V\left[O B_{1}+O B_{2}\right] \leq \alpha
$$

Where ${ }_{V}$ is the variance operator, and $\alpha$ the present tolerable variance level.

The total outlay should not exceed the budget since the corporation's available capital is limited. Thus we can ask that the expected outlay should not exceed the available capital and the variance value of the outlay should not exceed a preset tolerable level $\beta$. Note that if an existing project $i$ is given up, we can sell it and obtain a net income which can be used to support the other projects in the first year. Then we can express the budget control requirements as follows:

$$
\begin{aligned}
& E\left[\sum_{i=k+1}^{n} S_{0} a_{i} x_{i}+\sum_{i=1}^{k} x_{i} y_{i} S_{0} G O_{i}\right] \leq W_{0}+\sum_{i=1}^{k} B_{i}\left(1-x_{i}\right)+a \\
& V\left[\sum_{i=k+1}^{n} S_{0} a_{i} x_{i}+\sum_{i=1}^{k} x_{i} y_{i} S_{0} G O_{i}-\sum_{i=1}^{k} B_{i}\left(1-x_{i}\right)\right] \leq \beta
\end{aligned}
$$

Therefore, if the corporation asks that the return risk be controlled not to exceed the preset level and pursues the maximum expected investment profits in present form under the budget constraints, the corporation can adjust and select the projects via the following model.

$$
\left\{\begin{array}{l}
\max \quad E\left[O B_{1}+O B_{2}\right] \\
\text { Subject to: } \\
V\left[O B_{1}+O B_{2}\right] \leq \alpha \\
E\left[\sum_{i=k+1}^{n} S_{0} a_{i} x_{i}+\sum_{i=1}^{k} x_{i} y_{i} S_{0} G O_{i}\right] \leq W_{0}+\sum_{i=1}^{k} B_{i}\left(1-x_{i}\right)+a \\
V\left[\sum_{i=k+1}^{n} S_{0} a_{i} x_{i}+\sum_{i=1}^{k} x_{i} y_{i} S_{0} G O_{i}-\sum_{i=1}^{k} B_{i}\left(1-x_{i}\right)\right] \leq \beta \\
x_{i} \in\{0,1\}, \quad i=1,2, \ldots, n \\
y_{i} \in\{0,1\}, \quad i=1,2, \ldots, k
\end{array}\right.
$$

\section{NUMERICAL EXPERIMENTS}

Suppose company A is a Chinese multinational high-tech company. Now the company already has 5 independent projects in operation in America, and is considering selecting new projects from 5 candidate projects in America. Those 5 existing projects have been in operation for 3 years, and the lives of the projects (including 5 new candidate projects and upgraded projects) are all 10 years. The home country company rate for high-tech companies is $15 \%$ and the foreign country company rate is $35 \%$. The required rate in home country is $8 \%$. The normal interest rate of loan in home country is $6 \%$. The corporation's available own capital is 150 million RMB and the largest amount of loan granted is 300 million RMB. The initial construction cost for the new projects and the upgrade expenditures for the existing projects at the beginning of the investment year are normal random variables given in Table I. The net operating cash flows of the new projects and the existing projects if they are not adjusted are also normal random variables given in Table 2 . The increased proportion after upgrading is 0.5 . The future foreign exchange rate is also treated as normal random variables obey $N\left(0.1345,0.0135^{2}\right)$ (in the form of foreign country currency equivalent per unit of the home currency). The net income of the existing projects if they are abandoned is given in Table III. The spot foreign exchange rate is 
0.1553. The present tolerable variance levels $\alpha$ and $\beta$ equal to 35 million RMB and 1 million RMB, respectively.

TABLE I. INITIAL CONSTRUCTION COST AND UPGRADE EXPENDITURES (MILLION \$)

\begin{tabular}{|c|c|c|c|c|}
\hline Project 1 & Project 2 & Project 3 & Project 4 & Project 5 \\
\hline$N\left(23,2^{2}\right)$ & $N\left(27,2.5^{2}\right)$ & $N\left(30,3^{2}\right)$ & $N\left(32,3^{2}\right)$ & $N\left(23,2^{2}\right)$ \\
\hline Project 6 & Project 7 & Project 8 & Project 9 & Project 10 \\
\hline$N\left(54,2.5^{2}\right)$ & $N\left(62,3^{2}\right)$ & $N\left(52,2.5^{2}\right)$ & $N\left(58,3^{2}\right)$ & $N\left(48,2^{2}\right)$ \\
\hline
\end{tabular}

TABLE II. NET OPERATING CASH FLOWS (MILLION \$)

\begin{tabular}{|c|c|c|c|c|c|}
\hline Year & Project 1 & Project 2 & Project 3 & Project 4 & Project 5 \\
\hline 1 & $N\left(15,1.5^{2}\right)$ & $N\left(18,2^{2}\right)$ & $N\left(20,2.5^{2}\right)$ & $N\left(21,2.5^{2}\right)$ & $N\left(16,1.5^{2}\right)$ \\
\hline 2 & $N\left(15,1.5^{2}\right)$ & $N\left(18,2^{2}\right)$ & $N\left(20,2.5^{2}\right)$ & $N\left(21,2.5^{2}\right)$ & $N\left(16,1.5^{2}\right)$ \\
\hline 3 & $N\left(15,1.5^{2}\right)$ & $N\left(18,2^{2}\right)$ & $N\left(20,2.5^{2}\right)$ & $N\left(21,2.5^{2}\right)$ & $N\left(16,1.5^{2}\right)$ \\
\hline 4 & $N\left(15,1.5^{2}\right)$ & $N\left(18,2^{2}\right)$ & $N\left(20,2.5^{2}\right)$ & $N\left(21,2.5^{2}\right)$ & $N\left(16,1.5^{2}\right)$ \\
\hline 5 & $N\left(15,1.5^{2}\right)$ & $N\left(18,2^{2}\right)$ & $N\left(20,2.5^{2}\right)$ & $N\left(21,2.5^{2}\right)$ & $N\left(16,1.5^{2}\right)$ \\
\hline 6 & $N\left(15,1.5^{2}\right)$ & $N\left(18,2^{2}\right)$ & $N\left(20,2.5^{2}\right)$ & $N\left(21,2.5^{2}\right)$ & $N\left(16,1.5^{2}\right)$ \\
\hline 7 & $N\left(15,1.5^{2}\right)$ & $N\left(18,2^{2}\right)$ & $N\left(20,2.5^{2}\right)$ & $N\left(21,2.5^{2}\right)$ & $N\left(16,1.5^{2}\right)$ \\
\hline 8 & $N\left(15,1.5^{2}\right)$ & $N\left(18,2^{2}\right)$ & $N\left(20,2.5^{2}\right)$ & $N\left(21,2.5^{2}\right)$ & $N\left(16,1.5^{2}\right)$ \\
\hline 9 & $N\left(15,1.5^{2}\right)$ & $N\left(18,2^{2}\right)$ & $N\left(20,2.5^{2}\right)$ & $N\left(21,2.5^{2}\right)$ & $N\left(16,1.5^{2}\right)$ \\
\hline 10 & $N\left(15,1.5^{2}\right)$ & $N\left(18,2^{2}\right)$ & $N\left(20,2.5^{2}\right)$ & $N\left(21,2.5^{2}\right)$ & $N\left(16,1.5^{2}\right)$ \\
\hline Year & Project 6 & Project 7 & Project 8 & Project 9 & Project10 \\
\hline 1 & $N\left(18,2.2^{2}\right)$ & $N\left(22,3^{2}\right)$ & $N\left(17,2^{2}\right)$ & $N\left(19,2.5^{2}\right)$ & $N\left(15,1.5^{2}\right)$ \\
\hline 2 & $N\left(18,2.2^{2}\right)$ & $N\left(22,3^{2}\right)$ & $N\left(17,2^{2}\right)$ & $N\left(19,2.5^{2}\right)$ & $N\left(15,1.5^{2}\right)$ \\
\hline 3 & $N\left(18,2.2^{2}\right)$ & $N\left(22,3^{2}\right)$ & $N\left(17,2^{2}\right)$ & $N\left(19,2.5^{2}\right)$ & $N\left(15,1.5^{2}\right)$ \\
\hline 4 & $N\left(18,2.2^{2}\right)$ & $N\left(22,3^{2}\right)$ & $N\left(17,2^{2}\right)$ & $N\left(19,2.5^{2}\right)$ & $N\left(15,1.5^{2}\right)$ \\
\hline 5 & $N\left(18,2.2^{2}\right)$ & $N\left(22,3^{2}\right)$ & $N\left(17,2^{2}\right)$ & $N\left(19,2.5^{2}\right)$ & $N\left(15,1.5^{2}\right)$ \\
\hline 6 & $N\left(18,2.2^{2}\right)$ & $N\left(22,3^{2}\right)$ & $N\left(17,2^{2}\right)$ & $N\left(19,2.5^{2}\right)$ & $N\left(15,1.5^{2}\right)$ \\
\hline 7 & $N\left(18,2.2^{2}\right)$ & $N\left(22,3^{2}\right)$ & $N\left(17,2^{2}\right)$ & $N\left(19,2.5^{2}\right)$ & $N\left(15,1.5^{2}\right)$ \\
\hline 8 & $N\left(18,2.2^{2}\right)$ & $N\left(22,3^{2}\right)$ & $N\left(17,2^{2}\right)$ & $N\left(19,2.5^{2}\right)$ & $N\left(15,1.5^{2}\right)$ \\
\hline 9 & $N\left(18,2.2^{2}\right)$ & $N\left(22,3^{2}\right)$ & $N\left(17,2^{2}\right)$ & $N\left(19,2.5^{2}\right)$ & $N\left(15,1.5^{2}\right)$ \\
\hline 10 & $N\left(18,2.2^{2}\right)$ & $N\left(22,3^{2}\right)$ & $N\left(17,2^{2}\right)$ & $N\left(19,2.5^{2}\right)$ & $N\left(15,1.5^{2}\right)$ \\
\hline
\end{tabular}

TABLE III. Net INCOME OF EACH EXISTING PROJECT IF ABANDONED (MILLION \$)

\begin{tabular}{|c|c|c|c|c|c|}
\hline & Project1 & Project 2 & Project 3 & Project 4 & Project 5 \\
\hline$N_{i}$ & 30 & 35 & 32 & 31 & 68 \\
\hline
\end{tabular}

According to the model (23) in Section 2, we can obtain the result that the optimal solution is $X^{*}=(1,1,1,1,1,0,0,0,0,1,1,0,0,0,1)$. This means that in order to obtain the maximum expected NPV value under capital constraints and control risk, the corporation should keep the existing projects $1,2,3$ and 4 as they are $\left(x_{1}=1, y_{1}=0 ; x_{2}=1, y_{2}=0 ; x_{3}=1, y_{3}=0 ; x_{4}=1, y_{4}=0\right)$, upgrade the existing projects 5 ( $\left.x_{5}=1, y_{5}=1\right)$, and select new projects 6 and $10\left(x_{6}=x_{10}=1\right)$. The maximum expected NPV is 40.15308 million RMB.

\section{CONCLUSIONS}

This paper discussed the multinational project adjustment and selection problem under capital limitation with random project parameters and foreign exchange rates. Special cash flows and value sources of foreign projects are introduced, and a mean-variance optimal adjustment and selection model is developed.

\section{ACKNOWLEDGMENT}

This work was supported by National Natural Science Foundation of China Grants No. 70871011 and No. 71171018, Program for New Century Excellent Talents in University, and the Fundamental Research Funds for the Central Universities.

\section{REFERENCES}

[1] L.D. Booth, Capital budgeting frameworks for the multinational corporation, J. Int. Bus. Stud. 13 (1982) 113-123.

[2] M.W. Dickinson, A.C.Thornton, S.Graves, Technology portfolio management: Optimizing interdependent projects over multiple time periods. IEEE Trans. Eng. Manage. 48 (2001) 518-527.

[3] C.S. Eun, B.G. Resnick, International Financial Management, fifth ed., McGraw-Hill Education, New York, 2009.

[4] B. Gemici-Ozkan, S.D. Wu, J.T. Linderoth, J. Moorc, R\&D project portfolio analysis for the semiconductor industry. Oper. Res. 58 (2010) 1548-1563.

[5] J. Gutjahr, S. Katzensteiner, P. Reiter, C. Stummer, M. Denk, Multiobjective decision analysis for competence-oriented project portfolio selection, European J. Oper. Res. 205 (2010) 670-679.

[6] J. Holland, Capital budgeting for international business: a framework for analysis, Managerial Finance (ISSN: 0307-4358) 16 (1990) 1-6.

[7] X. Huang, Mean-variance model for fuzzy capital budgeting, Computers \& Industrial Engineering, Vol. 55, No. 1, 34-47, 2008.

[8] J.W.Lee, S.H. Kim, An integrated approach for interdependent information system project selection. Int. J.Project Manage.19(2001) 111-118.

[9] D.R. Lessard, Evaluating international projects: an adjusted present value approach, in: D.R. Lessard (Ed.), International Financial Management, second ed., Wiley, New York, 1985, pp. 570-584.

[10] M. Padberg, M.J. Wilczak, Optimal project selection when borrowing and lending rates differ, Math. Comput. Modelling 29 (1999) 63-78.

[11] M. Shakhsi-Niaei, S.A. Torabi, S.H. Iranmanesh, A comprehensive framework for project selection problem under uncertainty and realworld constraints. Comput. Ind. Eng. 61 (2011) 226-237.

[12] A.C. Shapiro, Capital budgeting for the multinational corporation, Finan. Manage. 7 (1978) 7-16.

[13] H.M. Weingartner, Mathematical Programming and the Analysis of Capital Budgeting Problems, Englewood Press, Prentice-Hall, 1963.

[14] Q. Zhang, X. Huang, L. Tang , Optimal Multinational Capital Budgeting under Uncertainty. Comput. Math. Appl.62 (2012) 45574567. 